\title{
C-CARE: comparing three years of anaphylaxis in children treated at the Montreal Children's Hospital
}

\author{
Sarah De Schryver ${ }^{1 \dagger}$, Elana Hochstadter ${ }^{2}$, Ann Clarke ${ }^{3}$, Sebastien LaVieille ${ }^{4}$, Reza Alizadehfar ${ }^{1}$, Alizee Dery ${ }^{5}$, \\ Christopher Mill ${ }^{6}$, Harley Eisman², Moshe Ben-Shoshan ${ }^{1^{*}+}$ \\ From Canadian Society of Allergy and Clinical Immunology Annual Scientific Meeting 2014 \\ Ottawa, ON, Canada. 23-26 October 2014
}

\section{Background}

The Cross-Canada Anaphylaxis Registry (C-CARE) aims to examine burden, triggers, management and temporal trends in anaphylaxis.

\section{Methods}

Over a three-year period (April 2011 to April 2014), data were collected on anaphylaxis cases at the Montreal Children's Hospital emergency department (ED). Cases were recruited either prospectively or identified retrospectively based on chart review through ICD10 codes related to anaphylaxis. Logistic regressions were conducted to determine the association between sociodemographic and clinical characteristics and development of severe reactions as well as epinephrine use.

\section{Results}

Among 624 cases the median age was 5.7 years (IQR 2.4-11.7) and the majority (56.6\%) were males. The percentage of anaphylaxis among all ED visits increased from $0.22 \%$ (95\% CI $0.18 \%, 0.24 \%)$ in 2011 to $0.3 \%$ (95\% CI $0.25 \%, 0.33 \%)$ in 2014, yielding a difference of $0.08 \%$ (95\%CI, $0.03 \%, 0.13 \%)$. The major trigger was food $(81.4 \%)$, mainly peanut and tree-nut. Most cases were moderate $(70.2 \%)$ (breathing difficulties, stridor, diarrhea, crampy abdominal pain, recurrent vomiting).

Of all reactions $28.7 \%$ were not administered epinephrine. Almost 95\% were prescribed or had an epinephrine auto-injector (71.6\% Epipen , 22.7\% Allerject).

\footnotetext{
+ Contributed equally

'Division of Allergy and Clinical Immunology, Department of Pediatrics, Montreal Children's Hospital, McGill University Health Center, Montreal, QC, Canada

Full list of author information is available at the end of the article
}

Factors associated with severe reactions included history of peanut allergy, asthma and steroid treatment in ED. (Table 1).

Management of anaphylaxis with at least one dose of epinephrine was associated with known food allergy and use of steroids in ED.

Administration of two or more epinephrine doses in ED was less likely in those who received epinephrine outside ED and more likely with severe reactions, reactions triggered by tree-nut and in those treated with steroids in ED.

\section{Conclusions}

The percentage of anaphylaxis cases among all ED visits increased by almost $40 \%$ over a three-year period. Prompt use of epinephrine may prevent use of subsequent

Table 1 Logistic regressions assessing severe reactions and use of epinephrine

\begin{tabular}{ll}
\hline Severe reactions & \\
\hline Variable & OR, 95\% CI \\
\hline Asthma & $2.3(1.5)$ \\
\hline Use of steroids in ED & $2.5(1.2,5.2)$ \\
\hline Peanut allergy & $2.2(1,4.9)$ \\
\hline No use of epinephrine & \\
\hline Use of steroids in ED & $0.2(0.1,0.4)$ \\
\hline Known food allergy & $0.3(0.2,0.5)$ \\
\hline Use of more than $\mathbf{2}$ epinephrine in ED & \\
\hline Use of epinephrine outside & $0.06(0.01,0.6)$ \\
\hline Use of steroids in ED & $9.0(2.6,31)$ \\
\hline Severe reaction & $16.8(4.7,61)$ \\
\hline Tree-nut allergy & $5.4(1.2,24)$ \\
\hline
\end{tabular}


multiple doses of epinephrine in ED. Reactions triggered by tree-nut are more prone to require treatment with multiple doses of epinephrine.

\section{Acknowledgment}

This project was supported by AllerGEN, Health Canada and Sanofi

\section{Authors' details}

'Division of Allergy and Clinical Immunology, Department of Pediatrics,

Montreal Children's Hospital, McGill University Health Center, Montreal, QC, Canada. ${ }^{2}$ Emergency Department, Department of Pediatrics, Montreal

Children's Hospital, McGill University Health Center, Montreal, QC, Canada.

${ }^{3}$ Division of Rheumatology, Department of Medicine, University of Calgary,

Calgary, AB, Canada. ${ }^{4}$ Food Directorate, Health Canada, Ottawa, ON, Canada.

${ }^{5}$ Department of Experimental Medicine, McGill University, Montreal, QC,

Canada. ${ }^{6}$ Department of Public Health, University of British Columbia,

Vancouver, BC, Canada.

Published: 18 December 2014

doi:10.1186/1710-1492-10-S2-A3

Cite this article as: De Schryver et al: C-CARE: comparing three years of anaphylaxis in children treated at the Montreal Children's Hospital.

Allergy, Asthma and Clinical Immunology 2014 10(Suppl 2):A3.

Submit your next manuscript to BioMed Central and take full advantage of:

- Convenient online submission

- Thorough peer review

- No space constraints or color figure charges

- Immediate publication on acceptance

- Inclusion in PubMed, CAS, Scopus and Google Scholar

- Research which is freely available for redistribution

Submit your manuscript at www.biomedcentral.com/submit 